\title{
Alternatively-Spliced p53 mRNA in the FAA-HTC1 Rat Hepatoma Cell Line without the Splice Site Mutations
}

\author{
Ikue Fukuda and Katsuhiro Ogawa* \\ Department of Pathology, Asahikawa Medical College, 4-5-3-11 Nishikagura, Asahikawa, 078 Japan
}

Key words: p53/RT-PCR/exon skipping/FAA-HTC1 cells/hepatoma

\begin{abstract}
$A B S T R A C T$. A novel mutation of the p53 gene has been found in a rat hepatoma cell line, FAA-HTC1. This cell line carried two kinds of abnormal p53 transcripts; one lacked the exon 8 sequence, and the other had a single base substitution $G$ to $T$ which resulted in a new stop codon in exon 8 . In the genomic DNA, this base substitution in exon 8 was present, indicating that both transcripts were transcribed from the mutated gene. No mutation was detected in its two flanking introns. In this cell line, the exon-deleted transcript seems to be generated by exon skipping due to an unknown mechanism other than splice site mutations.
\end{abstract}

Alterations of the p53 gene have been identified in a wide variety of human and animal cancers (1). Most aberrations are loss of the normal $\mathrm{p} 53$ allele and various mutations in the remaining allele (2). The mutations can be missense or nonsense mutations, and minor deletion. Most missense mutations are concentrated in four of the five evolutionally-conserved regions (2). Recently, a number of reports have described that some tumor cells have abnormally-spliced p53 (3-9), RB (10-14) and NF1 mRNAs $(15,16)$, indicating that abnormal splicing of mRNA precursors is one of the important mechanisms for inactivation or alteration of the function of tumor suppressor genes. Although most cases of abnormal splicing are due to splice site mutations $(3,6-11)$ or cell type-specific alternative splicing $(4,5,15,16)$, the abnormality in a few cases has been reported to be only a single base substitution which results in a new stop codon within the aberrantly-spliced exon (11-14).

In this study, we detected two kinds of abnormal p 53 transcripts (one with deletion of exon 8 and the other with the presence of a stop codon in exon 8 ) in a rat hepatoma cell line. To explore the cause of deletion of the exon, we investigated the genomic sequences including exon 8 , its two flanking introns and parts of exon $7 \& 9$ of the p 53 gene. We show that these two abnormal transcripts are transcribed from the common mutated gene, and that the abnormal splicing seems to occur by a mechanism other than splice site mutations.

\section{MATERIALS AND METHODS}

Samples. FAA-HTC1, a rat hepatoma cell line (17), and

\footnotetext{
* To whom correspondence should be addressed.
}

the liver of 6-week old male F344 rats were investigated for the $\mathrm{p} 53$ gene. For the normal liver, rats received a two-thirds partial hepatectomy $8-12 \mathrm{hr}$ before sacrifice to increase p53 mRNA (18).

Preparation of nucleic acids. DNA was extracted by the standard method using SDS, proteinase $\mathrm{K}$, phenol and chloroform. Poly $(\mathrm{A})^{+}$RNA was isolated using the Fast Track mRNA Isolation Kit (V2.0, Invitrogen).

Northern blot analysis. Poly (A) ${ }^{+}$RNA was subjected to electrophoresis under denaturing conditions. RNA transfer to a nylon membrane (Hybond- $\mathrm{N}^{+}$; Amersham), hybridization and autoradiographic identification were done by standard techniques (19). The filter was successively hybridized with [32P] labeled $\mathrm{p} 53$ and $\beta$-actin probes. The purified PCR product (the A fragments from wild type p53 cDNA) was used as a 553 probe.

Polymerase chain reaction (PCR): Samples of mRNA were annealed with random hexamer primers and transcribed with M-MLV reverse transcriptase (Bethesda Research Laboratories) in the presence of RNasin. A portion of the reaction mixture was subjected directly to PCR using appropriate oligonucleotide primers. PCR was carried out for 35 cycles of 1 min at $94^{\circ} \mathrm{C}, 1 \mathrm{~min}$ at $55^{\circ} \mathrm{C}$ and $1.5 \mathrm{~min}$ at $72^{\circ} \mathrm{C}$. The following PCR primers were prepared from the $\mathrm{p} 53 \mathrm{cDNA}$ sequence reported by Soussi et al. (20). For segment A (Fig. 1a), the sense primer $\left(5^{\prime}\right.$-TTACCAAGGCAACTATGGCT- $\left.3^{\prime}\right)$ was in exon 4 , and the anti-sense primer (5'-CTCAGGTGGCTCATACGGTA-3') was in exon 6 . For segment $B$, the sense primer (5'-TGGACGACAGGCAGACTTTT-3') was in exon 6, and the anti-sense primer (5'-CCACGGATCTTAAGGGTGAA$\left.3^{\prime}\right)$ was in exons 9-10. The sequence encompassing exons 7 to 9 was also amplified using the genomic DNA as a template (Fig. 1b). For this, the sense primer (5'-CTTACCATCATCACGCTGGA-3') was in exon 7, and the anti-sense primer (5'-G- 
GAGAGGAGCTTGTGCTGGT-3') was in exon 9. The exon boundaries in rat p53 cDNA were considered to be similar to the genomic sequence of the mouse p53 (21).

Southern blot analysis. PCR amplified cDNA was electrophoresed on agarose gel and transferred to nylon membranes (Hybond- $\mathrm{N}^{+}$; Amersham). The membranes were hybridized under stringent conditions with ${ }^{32} \mathrm{P}$ labelled oligonucleotide probe complementary to exon 7,8 or 9 which were 5 -CTTGTAGTGGATAGTGGTATAGTCGGA-3, 5'-AAATTTTCTTCCTCTGTCCGACGGTCT-3', and 5'-GGTGTAAATATTCTCCATCGAGTGGTT-3', respectively. Autoradiography was performed with an intensifying screen at $-80^{\circ} \mathrm{C}$.

Restriction enzyme assay. PCR products purified as already described were digested with $\mathrm{Mbo}$ II and electrophoresed on a $5 \%$ polyacrylamide gel.

Sequencing. PCR products were purified by separating them in $5 \%$ polyacrylamide gel. The purified PCR products were ligated into the Sma I site of the M13 mp18 vector using a DNA Blunting Kit (Takara) and transfected into E. coli JM109 cells. Three to five plaques were separately sequenced for each PCR product. Sequencing was performed bi-directionally by the dideoxy chain termination method using a Sequenase V2.0 Kit (U.S. Biochemical).

Immunoprecipitation. FAA-HTC1 cells and the hepatocytes isolated from partially hepatectomized rats $(8-12 \mathrm{hr}$ after operation) were metabolically labeled by culturing in methionine-free Dulbecco's medium containing $100 \mu \mathrm{Ci} / \mathrm{ml}$ $\left[{ }^{32} \mathrm{~S}\right]-$ methionine and $5 \%$ dialyzed fetal calf serum for $1 \mathrm{hr}$. The cell lysates were incubated for $30 \mathrm{~min}$ at $4^{\circ} \mathrm{C}$ with Protein A-Sepharose followed by incubation for $2-4 \mathrm{hr}$ at $4^{\circ} \mathrm{C}$ with Protein A-Sepharose coupled with anti-p53 monoclonal antibodies. The antibodies (Oncogene Science) used were Pab 421 reacting to both wild-type/mutated forms of $\mathrm{p} 53$, and $\mathrm{Pab}$ 240 reacting only to the mutated form. Following incubation, the Sepharose beads were extensively washed, then boiled for 5 min in water bath. The supernatants were subjected to $10 \%$ SDS-polyacrylamide gel electrophoresis and autoradiography.

a

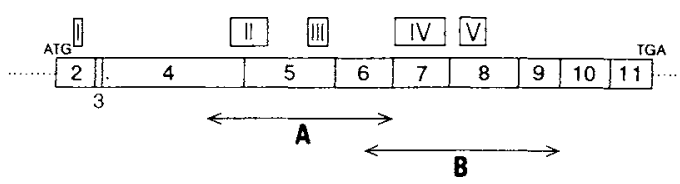

b

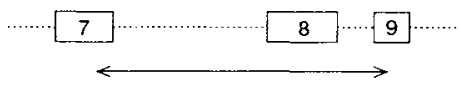

Fig. 1. a) The range of p53 cDNA amplified by PCR. DNA was amplified from two overlapping segments, A and B. b) The range of p53 genomic DNA for PCR amplification. Arabic numerals indicate exons, and Roman numerals the highly conserved regions.

\section{RESULTS AND DISCUSSION}

p53 transcripts were detected by Northern blot analysis in the regenerating liver, although they were not detected in FAA-HTC1 cells. However, the fragments of expected size were generated from p53 cDNA of FAAHTC1 cells by PCR, indicating that small amounts of p53 mRNA was present in this cell line (Fig. 2). The PCR product amplified from exons 4-6 (the A segment) was $367 \mathrm{bp}$ both in the regenerating liver and FAAHTC1 cells, and its DNA sequence was consistent to the normal rat p53 cDNA sequence (20). Amplification of exons 6-9 (the B segment) from the regenerating liver generated 385 bp DNA, whereas two fragments of 385 bp and 248 bp of almost equal intensity were amplified from the FAA-HTC1 cells (Fig. 3a). These two fragments were reproducibly generated from the FAA$\mathrm{HTCl}$ cells, indicating that they were not due to an error in reverse transcription or PCR. In Southern blot analysis, the 248 bp DNA from FAA-HTC1 cells reacted with the exon 7 and 9 probes, but not to the exon 8 probe (Fig. 3 b). The 248 bp band could not be detected in the regenerating liver in spite of prolonged exposure when probed with exon 7 or 9 specific probes (Fig. 3c).

Sequencing revealed that the $385 \mathrm{bp}$ fragments from FAA-HTC 1 cells have a $G$ to $T$ transversion at the first nucleotide of codon 291 in exon 8 . The same fragment from the regenerating liver did not show a mutation at codon 291 (Fig. 4a). This substitution must lead to the conversion of the glutamic acid codon (GAA) to a stop codon (TAA) resulting in a loss of one of the four MboII restriction sites within the $\mathrm{B}$ fragments. This was confirmed by restriction enzyme digestion (data not

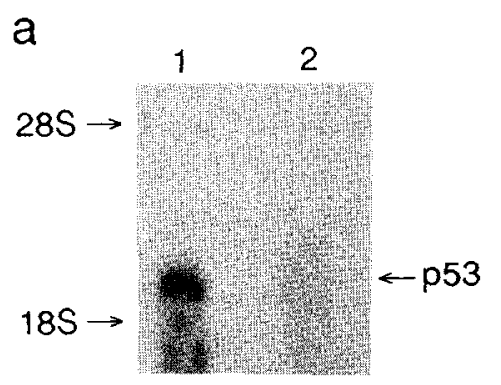

b

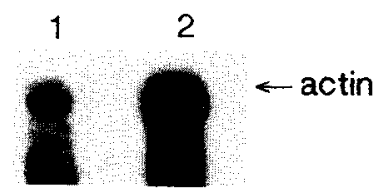

Fig. 2. Northern blot analysis of p 53 mRNA (a) and $\beta$-actin mRNA (b) in regenerating liver (1) and FAA-HTC1 cells (2). The positions of $28 \mathrm{~S}$ and $18 \mathrm{~S}$ rRNA are indicated. 
a

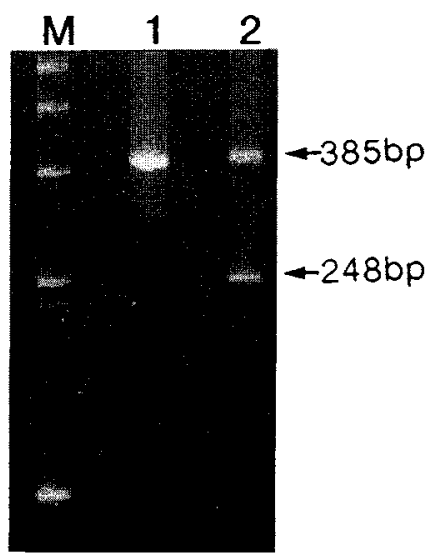

b

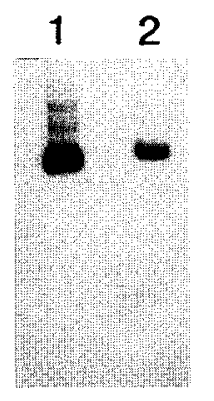

C

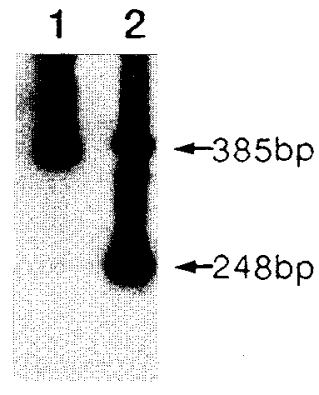

Fig. 3. a) DNA from the B segment in Fig. 1a. Only one band ( $385 \mathrm{bp}$ ) is detected in the regenerating liver (lane 1 ), but two bands ( 385 and 248 bp) are seen in FAA-HTC1 cells (lane 2). Molecular weight markers (M). b, c) Southern blot analysis of the B segment DNA with the exon 8 probe (b) and with the exon 9 probe (c). Regenerating liver (lane 1) and FAA-HTC1 cells (lane 2). The 248 bp DNA of FAA-HTC1 cells does not hybridize to the exon 8 probe (b, lane 2), but does react to the exon 9 probe (c, lane 2). The 248 bp DNA is not present in the regenerating liver (b, $c$, lane 1).

shown). On the other hand, DNA sequence of the 248 bp fragment from FAA-HTC1 cells showed direct connection between exons 7 and 9 indicating that they had been generated by the loss of $137 \mathrm{bp}$ corresponding to exon 8 (Fig. 4b).

PCR amplification of the genomic DNA encompassing the sequence from exon 7 to exon 9 generated the dominant $576 \mathrm{bp}$ and minor $187 \mathrm{bp}$ species in the regenerating liver and FAA-HTC1 cells. Sequencing of the $576 \mathrm{bp}$ DNA from the regenerating liver revealed that it contained exon 8 , its two flanking introns and parts of exons 7 and 9 (Fig. 5a). Intron 7 was 309 bp, whereas in- tron 8 was 78 bp in which the distance from the 5 splice site to the presumptive branching point was 55 bp (Fig. 5a). However, the 576 bp DNA from FAA-HTC1 cells showed the $G$ to $T$ transversion at codon 291 in exon 8 as seen in the cDNA. These results were also confirmed by the MboII restriction enzyme assay (data not shown). This result was duplicated in two separate amplification and sequencing experiments. We could not identify any other difference except for the G to T transversion at codon 291 when comparing the 576 bp DNA between FAA-HTC1 cells and the regenerating liver. Therefore it can be concluded that the two transcripts in

\section{a}

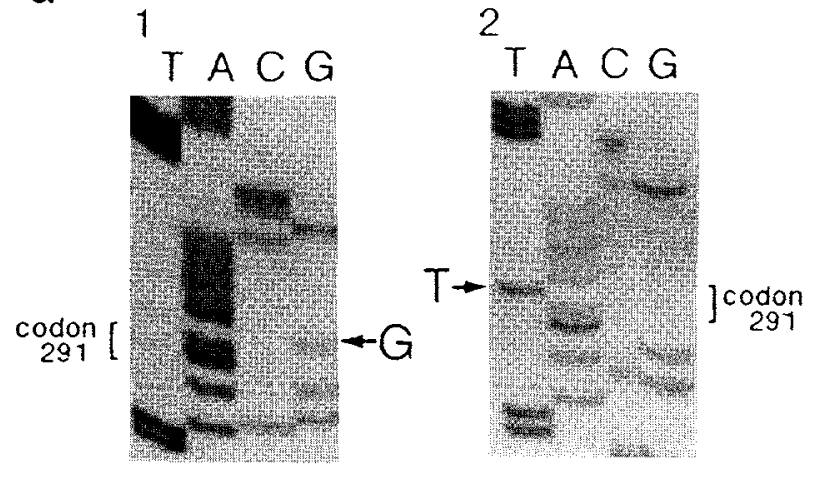

b

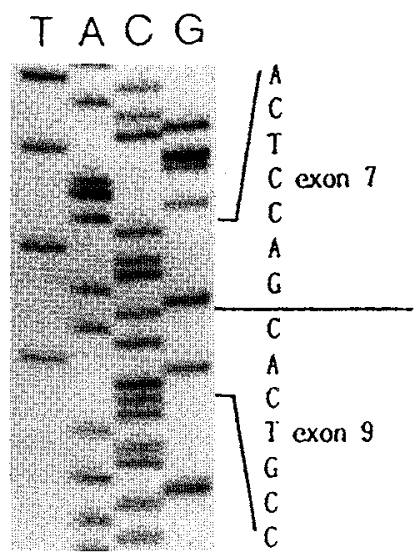

Fig. 4. a) Sequence of the 385 bp DNA in Fig. 3a from the regenerating liver (1) and FAA-HTC1 cells (2). The $G$ to $T$ transversion is seen at the first base of codon 291 in FAA-HTC1 cells. b) Sequence of the 248 bp fragments of FAA-HTC1 cells in Fig. $3 a$. Exons 7 and 9 are directly connected without exon 8 . 
FAA-HTC1 cells are transcribed from the mutated gene, and that the deletion of exon 8 in one of the transcripts is due to exon skipping during processing of the p53 pre-mRNA.

The sequence of the $187 \mathrm{bp}$ DNA from the regenerating liver and FAA-HTC1 cells were the same, showing $82 \%$ homology to exons $7-9$ of the p53 cDNA without

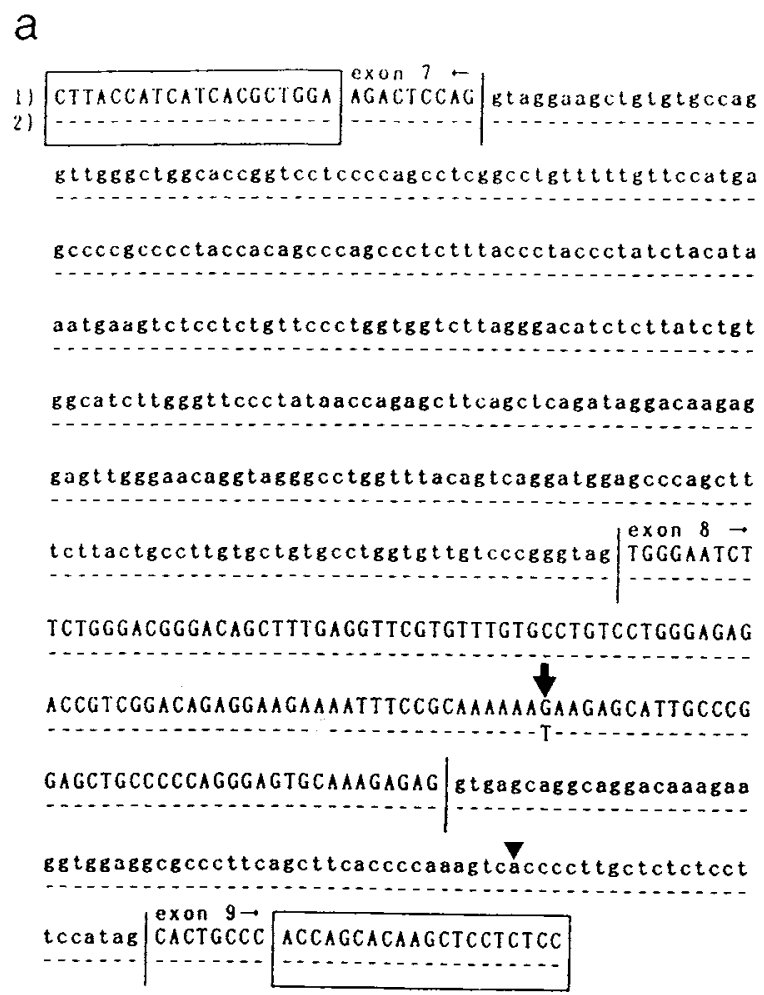

b

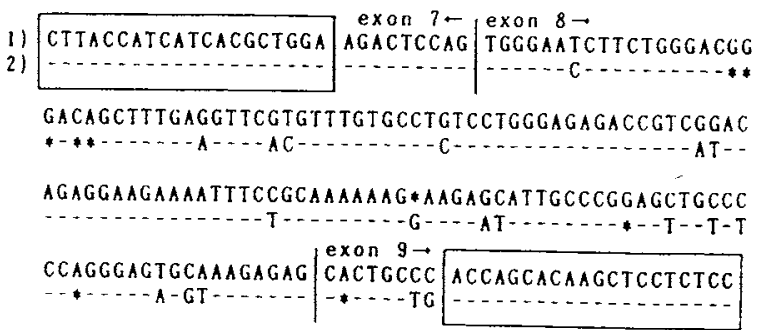

Fig. 5. a) Sequence of $p 53$ genomic DNA from exon 7 to exon 9 in F344 rat (1) and FAA-HTC1 cells (2). Open boxes are PCR primers, and capital and small letters are sequences of exons and introns, respectively. A bold arrow denotes the $G$ to $T$ transversion at codon 291 , and an arrowhead shows the presumptive branching site of intron 8. b) Sequence of normal p 53 cDNA (1) and that of the $p 53$ pseudogene (2). The nucleotides differing from the normal cDNA are only detailed in the pseudogene sequence. Asterisks denote gaps introduced in the sequence for better alignment. Boxes are the PCR primers. introns (Fig. 5b). Therefore, this sequence was thought to be derived from a p53 pseudogene.

Introduction of the stop codon at codon 291 or skipping of exon 8 during transcription must have resulted in truncated proteins. The truncated protein with $282 \mathrm{a}-$ mino acids might be generated from the exon skipped transcripts, because a new termination codon was thought to occur in exon 9. However, neither a normal size nor altered $\mathrm{p} 53$ protein was detected by immunoprecipitation in this cell line (Fig. 6). As p53 mRNA level was so low as to be detected by Northern blot analysis in this cell line, the absence of p53 protein in immunoprecipitation was thought to be due to real loss rather than antigenic changes of the protein. It was also possible that such altered proteins, if generated, were broken down within a short period.

In FAA-HTC1 cells, exon skipping seems to occur without abnormalities of the splice sites. To our knowledge, similar exon skipping has been documented for the RB gene in four cell lines (11-14). In these cells, a single base substitution, which leads to a new stop codon, has been identified in the genomic sequence of the skipped exon. In addition, the normal RB gene had been deleted, and no abnormalities have been identified at the splice sites. In those cell lines as well as FAAHTC1, it is thought that the base change, rather than the generation of a new stop codon, somehow prevents the recognition of the splice site by the splicing machinery, and the sequence including the exon and its flanking introns must be recognized as a single intron. Exon mutations also has been reported to affect splicing of SV40 late antigen, fibronectin, $\beta$-globin, acetyl CoA dehydrogenase and dystrophin pre-mRNA (22-26). We also think that, in the case of FAA-HTC1 cells, the

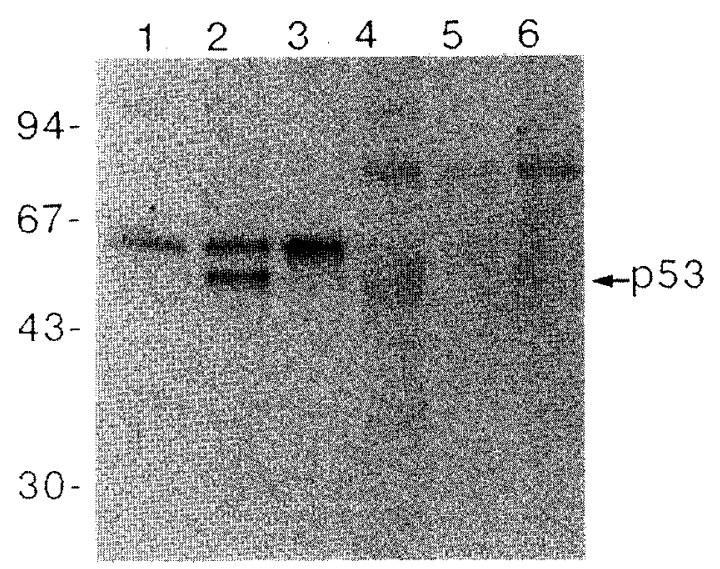

Fig. 6. Immunoprecipitation of $\mathrm{p} 53$ for the regenerating liver (lanes 1-3) and FAA-HTC1 cells (lanes 4-6). The cell lysates were immunoprecipitated with normal mouse serum (lanes 1 and 4), Pab 421 (lanes 2 and 5) and Pab 240 (lanes 3 and 6). No p53 is seen in FAA-HTC1 cells. 
short distance $(55 \mathrm{nt})$ between the $5^{\prime}$ splice site and the putative branching point of intron 8 can favor the abnormal splicing (Fig. 5a), because it has been shown that the length between these two points must be more than 50nt for U1 and U2 RNPs to interact to form lariats (27).

In addition to these cis factors, it is also possible that transformation-associated or cell type-specific alternative splicing can also be responsible for the exon skipping (27). Differential splicing of p53 pre-mRNA has been described in the murine Friend erythroleukemia cells which had been treated and untreated by dimethyl sulfoxide for differentiation (4). Alternative splicing of p53 pre-mRNA has also been shown at the acceptor site of intron 2 in the normal human fibroblasts (5). Further studies must be needed to clarify the mechanism, but the unique exon skipping recognized in FAA-HTC1 cells as well as in other cell lines would imply that this type of mutation is one of the important mechanisms for inactivation of the function of tumor suppressor genes.

Acknowledgments. We thank Dr. K. Furukawa and Dr. Y. Mochizuki (Sapporo Medical College) for providing FAA-HTC1 cells, and Dr. M. Kitagawa (Banyu Pharmaceutical Co., Ltd.) for valuable advice about immunoprecipitation of $\mathrm{p} 53$. This work was supported by grants from the Ministry of Education, Culture and Science of Japan, the Hokkaido Geriatric Research Institute, the Ono Cancer Research Foundation and the Suhara Memorial Foundation.

\section{REFERENCES}

1. Levine, A.J., Momand, J., and Finlay, C.A. (1991). The p53 tumour suppressor gene. Nature, 351: 453-456.

2. Nigro, J.M., Baker, S.J., Preisinger, A.C., Jessup, J.M., Hostetter, R., Cleary, K., Bigner, S.H., Davidson, N., Baylin, S., Devilee, P., Glover, T., Collins, F.S., Weston, A., Modali, R., Harris, C.C., and Vogelstein, B. (1989). Mutations in the $p 53$ gene occur in diverse human tumour types. Nature, 342: 705-709.

3. Arai, N., Nomura, D., Yokota, K., Wolf, D., Brill, E., SHOHAT, O., and ROTTER, V. (1986). Immunologically distinct p53 molecules generated by alternative splicing. Mol. Cell. Biol., 6: 3232-3239.

4. BeNDORI, R., RESNITZKY, D., and KIMCHI, A. (1987). Changes in p53 mRNA expression during terminal differentiation of murine erythroleukemia cells. Virology, 161: 607-611.

5. Matlashewski, G., Pim, D., Banks, L., and Craford, L. (1987). Alternative splicing of human p53 transcripts. Oncogene Res., 1: 77-85.

6. Foti, A., Bar-Eli, M., Ahuja, H.G., and Cline, M.J. (1990). A splicing mutation accounts for the lack of p53 gene expression in a CML blast crisis cell line: a novel mechanism of p53 gene inactivation. Brit. J. Haematol., 76: 143-145.

7. Sameshima, Y., AkiYama, T., Mori, N., Mizoguchi, H., Toyoshima, K., Sugimura, T., Terada, M., and Yokota, J. (1990). Point mutation of the $\mathrm{p} 53$ gene resulting in splicing inhibition in small cell lung carcinoma. Biochem. Biophys. Res. Commun., 173: 697-703.
8. Takahashi, T., D'Amico, D., Chiba, I., Buchhagen, D.L., and MinNA, J.D. (1990). Identification of intronic point mutations as an alternative mechanism for $\mathrm{p} 53$ inactivation in lung cancer. J. Clin. Invest., 86: 363-369.

9. Ishioka, C., Sato, T., Gamoh, M., Suzuki, T., Shibata, H., Kanamaru, R., WaKui, A., and Yamazaki, T. (1991). Mutations of the p53 gene, including an intronic point mutation, in colorectal tumors. Biochem. Biophys. Res. Commun., 177: 901-906.

10. Dunn, J.M., Phillips, R.A., Zhu, X., Becker, A., and Galdie, B.L. (1989). Mutations in the RB1 gene and their effects on transcription. Mol. Cell. Biol., 9: 4596-4604.

11. Yandell, D.W., Campbell, T.A., Dayton, S.H., Petersen, R., Walton, D., Little, J.B., MCConkie-Rosell, A., BUCKLEY, E.G., and DRYJA, T.P. (1989). Oncogenic point mutations in the human retinoblastoma gene: their application to genetic counseling. New Engl. J. Med., 321: 1689-1695.

12. Bookstein, R., Shew, J-Y., Chen, P-L., Scully, P., and Lee, W-H. (1990). Suppression of tumorigenicity of human prostate carcinoma cells by replacing a mutated RB gene. Science, 247: 712-715.

13. Mori, N., Yokota, J., Akiyama, T., Sameshima, Y., Okamoto, A., Mizoguchi, H., Toyoshima, K., Sugimura, T., and Terada, M. (1990). Variable mutations of the RB gene in small-cell lung carcinoma. Oncogene, 5: 1713-1717.

14. Murakami, Y., Katahira, M., Makino, R., Hayashi, K., HIROHASHI, S., and SEKIYA, T. (1991). Inactivation of the retinoblastoma gene in a human lung carcinoma cell line detected by single-strand conformation polymorphism analysis of the polymerase chain reaction product of cDNA. Oncogene, 6: 37-42.

15. Nishi, T., Lee, P.S.Y., OKa, K., Levin, V.A., TANase, S., Morino, Y., and SAYA, H. (1991). Differential expression of two types of the neurofibromatosis type 1 (NF1) gene transcripts related to neuronal differentiation. Oncogene, 6: 1555-1559.

16. Suzuki, Y., Suzuki, H., Kayama, T., Yoshimoto, T., and Shibahara, S. (1991). Brain tumors predominantly express the neurofibromatosis type 1 gene transcripts containing the 63 base insert in the region coding for GTPase activating protein-related domain. Biochem. Biophys. Res. Commun., 181: 955-961.

17. Furukawa, K., Kodama, T., Yokol, T., and Mochizuki, Y. (1987). Some properties of a cell line and its clones established from the hepatocellular carcinoma induced in the rat by 2-acetylaminofluorene-effect of dexamethasone-. Tumor Res., 22 : 71-86.

18. Thompson, N.L., Mead, J.E., Braum, L., Goyette, M., Shank, P.R., and Fausto, N. (1986). Sequential protooncogene expression during rat liver regeneration. Cancer Res., 46: 3111-3117.

19. SambrooK, J., Fritsh, E.F., and Maniatis, T. (eds.). (1989). Molecular Cloning: A Laboratory Manual, Ed. 2. Cold Spring Harbor Laboratory, Cold Spring Harbor, NY.

20. Soussi, T., De Fromentel, C.C., Breugnot, C., and May, E. (1988). Nucleotide sequence of a cDNA encoding the rat p53 nuclear oncoprotein. Nucleic Acids Res., 16: 11384.

21. ZaKut-Houri, R., Oren, M., Bienz, B., Lavie, V., Hazum, S., and Givol, D. (1983). A single gene and a pseudogene for the cellular tumor antigen p53. Nature, 306: 594-597.

22. Somasekhar, M.B. and MERTZ, J.E. (1985). Exon mutations that affect the choice of splice sites used in processing the SV40 late transcripts. Nucleic Acids Res., 13: 5591-5609.

23. Mardon, H.J., Sebastio, G., and Baralle, F.E. (1987). A role for exon sequences in alternative splicing of the human 
fibronectin gene. Nucleic Acids Res., 15: 7725-7733.

24. Parent, A., Zeitlin, S., and Efstratladis, A. (1987). Minimal exon sequence requirements for efficient in vitro splicing of mono-intronic nuclear pre-mRNA. J. Biol. Chem., 262: 1128411291.

25. Kelly, D.P., Whelan, A.J., Ogden, M.L., Alpers, R., Zhang, Z., Bellus, G., Gregersen, N., Dorland, L., and Strauss, A.W. (1990). Molecular characterization of inherited medium-chain acyl-CoA dehydrogenase deficiency. Proc. Natl. Acad. Sci. USA, 87: 9236-9240.
26. Matsuo, M., Masumura, T., Nishio, H., Nakajima, T., Kitoh, Y., TaKumi, T., Koga, J., and NaKamura, $\mathbf{H}$. (1991). Exon skipping during splicing of dystrophin mRNA precursor due to an intraexon deletion in the dystrophin gene of Duchenne muscular dystrophy Kobe. J. Clin. Invest., 87: 21272131.

27. Sмith, C.W.J., Patton, J.G., and Nadal-Ginard, B. (1989). Alternative splicing in the control of gene expression. Annu. Rev. Genet., 23: 527-577.

(Received for publication, April 28, 1992

and in revised form, November 13,1992 ) 